\title{
Estimation of Drought Change Trends in Northeast China in 2020-2050 and Its Impact on Maize Yield
}

\author{
Zhulei Dong1, Yanling Song2*, Jinfeng Tian ${ }^{3}$ \\ ${ }^{1}$ Inner Mongolia Climate Centre, China Meteorological Administration, Hohhot, China \\ ${ }^{2}$ Chinese Academy of Meteorological Sciences, China Meteorological Administration, Beijing, China \\ ${ }^{3}$ Kiel University, Kiel, Germany \\ Email: *songyl@cma.gov.cn
}

How to cite this paper: Dong, Z. L., Song, Y. L., \& Tian, J. F. (2018). Estimation of Drought Change Trends in Northeast China in 2020-2050 and Its Impact on Maize Yield. Journal of Geoscience and Environment Protection, 6, 185-201.

https://doi.org/10.4236/gep.2018.612016

Received: September 20, 2018 Accepted: December 26, 2018

Published: December 29, 2018

Copyright $\odot 2018$ by authors and Scientific Research Publishing Inc. This work is licensed under the Creative Commons Attribution International License (CC BY 4.0).

http://creativecommons.org/licenses/by/4.0/

\begin{abstract}
Based on the results of nine Coupled Model Intercomparison Project Phase 5 (CMIP5) coupling models, the temperature and precipitation data of 114 stations in Northeast China were compared and analyzed. The simulation effect of CMIP5 model on precipitation and temperature in Northeast China was evaluated. The research shows that the Geophysical Fluid Dynamics Laboratory Earth System Models (GGFDL-ESM2G) have the best simulation effect on precipitation and temperature in Northeast China. Based on the SPEI index, the relationship between the drought trend of maize growing season and the yield change rate of maize in Northeast China was analyzed, and the future drought (2020-2050) and corn yield in Northeast China were estimated. The cumulative Standardized Precipitation Evapotranspiration Index (SPEI) analysis of the northeast maize growing season (May-September) shows that the drought in the northeastern region showed an intensifying trend from 1980 to 2010 , especially in the first ten years of the $21^{\text {st }}$ century. The cumulative SPEI index has a significant positive correlation with the yield of maize in Northeast China, and has a certain indicator effect on the yield of maize in Northeast China. The three scenarios of GFDL-ESM2G model show that under the three scenarios of Representative Concentration Pathways (RCP), the warming in Northeast China is significant; under the RCP4.5 scenario, the precipitation in Northeast China is increasing; in the RCP2.6 and RCP8.5 climate scenarios, precipitation is presented and reduces the trend of drought. Estimates of drought trends in Northeast China show that under the RCP4.5 climate scenario, the drought in Northeast China showed a slowing trend from 2020 to 2050 . Under the RCP2.6 and RCP8.5 climate scenarios, the drought in Northeast China showed an increasing trend. Under the RCP2.6
\end{abstract}


and RCP8.5 climate scenarios, the yield change rate of maize in Northeast China showed a downward trend, indicating that climate warming caused the drought in Northeast China to increase, which had a negative impact on corn yield increase. In severe drought years, drought may cause northeast corn production seriously reduced. However, under the RCP4.5 scenario, drought has little effect on corn yield.

\section{Keywords}

Northeast China, CMIP5 Model, SPEI, Corn Yield, Trend Estimation

\section{Introduction}

Northeast China is an important commodity grain production base in China and the largest producer of corn, of which corn production accounts for about $30 \%$ of the country's corn production. The abundance of corn in Northeast China is directly related to China's total corn production and national food security (Zhang et al., 2016). Global warming has been evident for nearly half a century. The Intergovernmental Panel on Climate Change (IPCC) Phase V report (2013) pointed out that the global surface warming rate from 1951 to 2012 was about twice the rate of warming since 1880 . On the one hand, climate warming has increased the heat resources in the northeast region, which has led to an increase in northeast corn production. On the other hand, climate warming is accompanied by extreme events such as drought, flooding and cold damage (Cheng et al., 2005). However, with the warming of the northeast corn growing season, the number, frequency and frequency of chilling damage in Northeast maize have decreased significantly in the past 30 years (Yu et al., 2017). Yang Yuyun et al. (2015) pointed out that before the 1990s, there was old and cold damage in the northeastern summer, which sometimes affected the growth and development of corn. However, in the past 20 years, with the warming of the climate, drought has become the main agro-meteorological disaster during the growth period of maize in Northeast China.

Since 1990, the drought trend has increased in Northeast China due to reduced precipitation and rising temperatures (Yu et al., 2014). It can be seen that the occurrence of drought is not only directly related to the amount of precipitation, but also indirectly related to the increase in evaporation caused by rising temperatures. The Standardized Precipitation Evapotranspiration Index (SPEI) is based on the Standardized Precipitation Index (SPI), which calculates the monthly water deficit, i.e. the monthly precipitation and the monthly evaporation. The difference, instead of the monthly precipitation in the SPI calculation, can more objectively describe the current surface dry and wet changes. Wang Lin and Chen Wen (2014) also pointed out that the SPEI index can describe the drought more accurately than the SPI index. Compared with the Palmer Drought Severity Index (PDSI), the SPEI index has multiple time scale features, 
and the calculation is simpler. Liu Wei and Jiang Dabei (2015) used the SPEI index to analyze the changes in dry and wet conditions in China, pointing out that there is a tendency to dry out in China as a whole, and the central, northern and northeastern regions of Inner Mongolia have significantly dried up. Sun Binfeng et al. (2015) found that the northeastern region showed an overall drought trend by analyzing the SPEI index at various time scales, especially after entering the 21 st century. In summary, the northeast region is experiencing a severe drought situation. How does the northeast drought affect the production of local major crop corn? How will the pattern of drought in the Northeast change in the future? $\mathrm{Hu}$ Shi et al. (2015) analyzed the temporal and spatial variation characteristics of drought in northern China under the three scenarios of IPCC (A1B, A2 and B1) in 2011-2050 based on WCRP coupled model data. At present, the study of drought in Northeast China is mainly concentrated on the relationship between drought and meteorological factors, drought evolution trend, and drought-time and space characteristics. There are few studies on drought and corn yield in maize growth stage, and there is little prediction of future maize yield in Northeast China in this study. On the one hand, this paper aims to use the fitting analysis of SPEI index and corn yield to explore the temporal and spatial characteristics and regularity of drought evolution in maize growing season in Northeast China, and to reveal the correlation between SPEI index and corn yield change rate in maize growing season. The feasibility and effectiveness of drought monitoring in the corn growing season in Northeast China provide a theoretical basis for the rational distribution of maize production in Northeast China and the risk management of drought prevention and mitigation. On the other hand, the CMIP5 model data will be used to estimate the future drought trends and corn yields in Northeast China, revealing the future yield changes of Northeast maize.

\section{Materials and Methods}

\subsection{Materials and Methods}

The research area of this paper is Northeast China, including the three eastern provinces (Heilongjiang Province, Jilin Province, Liaoning Province) and the eastern Inner Mongolia region (east of $115^{\circ} \mathrm{E}$ ), which is the main maize growing area in China. This paper uses nine CMIP5 coupling model data from China $\left(15.5^{\circ}-55.5^{\circ} \mathrm{N}, 70^{\circ} \mathrm{E}-140^{\circ} \mathrm{E}\right)$, including the $20^{\text {th }}$ century historical climate (historical, 1961-2005) and the typical concentration path (RCP) under 2006-2099 (from China National Climate Center). Temperature and precipitation data, CMIP5 uses four typical concentration path scenarios, namely RCP2.6, RCP4.5, RCP6.5 and RCP8.5 scenarios. The four RCPs, RCP2.6, RCP4.5, RCP6, and $\mathrm{RCP} 8.5$, are named after a possible range of radiative forcing values in the year 2100 relative to pre-industrial values $\left(+2.6,+4.5,+6.0\right.$, and $+8.5 \mathrm{~W} / \mathrm{m}^{2}$, respectively). This paper mainly uses RCP2.6 low emission scenario and RCP4.5 low emission scenario. And the RCP8.5 high emission scenario, the drought trend and corn yield in Northeast China are estimated. The model information is 
shown in Table 1. All pattern data is interpolated by bilinear interpolation onto a 1olo horizontal grid.

In order to evaluate the ability of the CMIP5 model to simulate precipitation and temperature in the eastern region, data on daily precipitation and temperature stations at 217 stations in the Northeast region from 1961 to 2005 were used. Since the site is dense and the pattern data is interpolated to the site, the 114 stations are selected for comparison according to the nearest principle of the site-to-grid center point (Figure 1). In addition, corn yield data were collected from 65 counties and cities in the Northeast. The growth period of corn is from May to September.

Table 1. Introduction to nine modes in CMIP5.

\begin{tabular}{ccc}
\hline Mode name & Unit and country & Resolution \\
\hline MACCESS1-0 & CSIRO-BOM, Australia & $192 \times 145$ \\
BCC-CSM1-1 & BCC, China & $128 \times 64$ \\
CCSM4 & NCAR, United States & $288 \times 192$ \\
CSIRO-Mk3-6-0 & CSIRO-QCCCE, Australia & $192 \times 96$ \\
GFDL-ESM2G & NOAA GFDL, United States & $144 \times 90$ \\
IPSL-CM5A-MR & IPSL, France & $144 \times 143$ \\
MPI-ESM-LR & MPI-M, Germany & $192 \times 96$ \\
MRI-CGCM3 & MRI, Japan & $320 \times 160$ \\
NorESM1-M & NCC, Norway & $144 \times 96$ \\
\hline
\end{tabular}

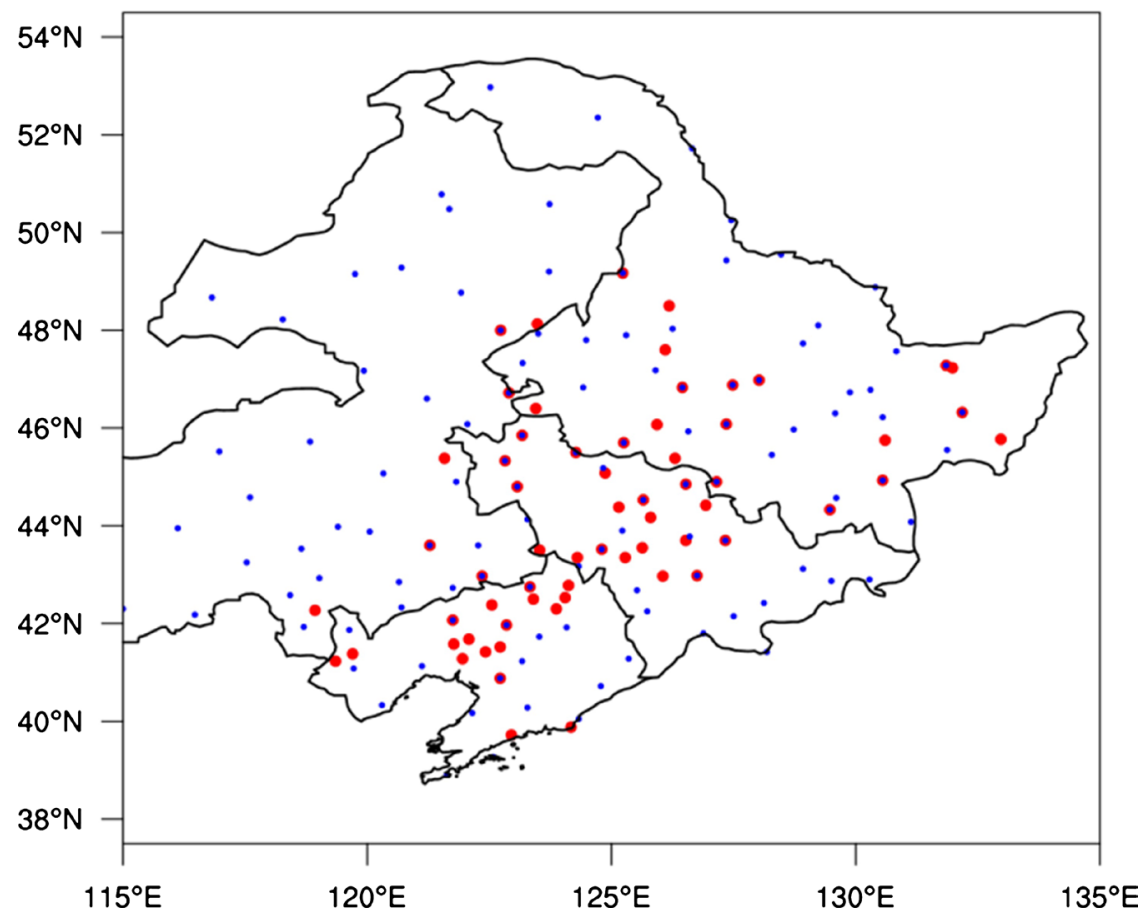

Figure 1. Distribution of corn yields in the 114 meteorological stations (blue dots) and stations (red dots) in Northeast China. 


\subsection{SPEI Index Calculation Method}

See Vicente Serrano et al. (2010). First, use the improved Thornthwaite (1948) to calculate the monthly evaporation potential PET (Potential Evapotranspiration, PET, unit: $\mathrm{mm})$, namely:

$$
P E T=16 K\left(\frac{10 T}{I}\right)^{m}
$$

In the formula, $T$ is the monthly average temperature $\left({ }^{\circ} \mathrm{C}\right), I$ is the annual heat index, which is obtained by summing up the 12 months index. The formula for calculating the index is:

$$
i=\left(\frac{T}{5}\right)^{1.514}
$$

$m$ is the constant determined by $I$, and $K$ is the correction factor, the formula is:

$$
K=\left(\frac{N}{12}\right)\left(\frac{N D M}{30}\right)
$$

$N D M$ is the total number of days in the month, $N$ is the number of hours that can be sunshine, and the calculation formula is:

$$
N=\left(\frac{24}{\pi}\right) \varpi_{s}
$$

$\varpi_{s}$, for the sunrise angle, the formula is:

$$
\varpi_{s}=\arccos (-\tan \varphi \tan \delta)
$$

$\varphi$ is latitude (radian)and $\delta$ is the solar magnetic declination, the formula is:

$$
\delta=0.4093 \sin \left(\frac{2 \pi J}{365}-1.405\right) .
$$

$J$ is the average date of the month.

Secondly, calculate the water deficit $(\mathrm{mm})$, the water deficit is the difference between the monthly precipitation $P$ and the monthly evaporation $P E T$, that is, the water deficit in the first month is:

$$
D_{i}=P_{i}-P E T_{i}
$$

It is then possible to construct a $k$ sequence of cumulative water deficits $X_{i, j}^{k}$ for a certain month $j$ and time $k$ of the year $i$,

Namely,

$$
\left\{\begin{array}{l}
X_{i, j}^{k}=\sum_{l=13-k+j}^{12} D_{i-1, l}+\sum_{l=1}^{j} D_{i, l}, j<k \\
X_{i, j}^{k}=\sum_{l=j-k+1}^{j} D_{i, l}, j \geq k
\end{array}\right.
$$

A three-parameter log-logistic probability distribution function is introduced to calculate the probability distribution of the cumulative water deficit sequence. 
The log-logistic probability density function is:

$$
f(x)=\frac{\beta}{\alpha}\left(\frac{x-\gamma}{\alpha}\right)^{\beta-1}\left[1+\left(\frac{x-\gamma}{\alpha}\right)^{\beta}\right]^{-2}
$$

Among them, $\alpha, \beta$ and $\gamma$ are scale parameters, shape parameters and position parameters. , and the calculation formula is:

$$
\begin{gathered}
\beta=\frac{2 w_{1}-w_{0}}{6 w_{1}-w_{0}-6 w_{2}} \\
\alpha=\frac{\left(w_{0}-2 w_{1}\right) \beta}{\Gamma\left(1+\frac{1}{\beta}\right) \Gamma\left(1-\frac{1}{\beta}\right)} \\
\gamma=w_{0}-\alpha \Gamma\left(\frac{1+1}{\beta}\right) \Gamma\left(\frac{1-1}{\beta}\right)
\end{gathered}
$$

Among them, $w_{s}$ is the probability weight moment, $s=1,2,3$, and the calculation formula is:

$$
w_{s}=\frac{1}{N} \sum_{i=1}^{N}\left(1-\frac{i-0.35}{N}\right) D_{i}
$$

$i$ is the ordinal number of the cumulative water deficit sequence in ascending order, which is the number of data points, which is the Gamma function. The three-parameter log-logstic probability distribution function is:

$$
F(x)=\left[1+\left(\frac{\alpha}{x-\gamma}\right)^{\beta}\right]^{-1}
$$

Finally, the probability distribution of the cumulative water deficit series for each month $F(x)$ is standardized. Order $P=1-F(x)$, at the time $P \leq 0.5$, parameters $W=\sqrt{-2 \ln P}$,

$$
S P E I=W-\frac{c_{0}+c_{1} W+c_{2} W^{2}}{1+d_{1} W+d_{2} W^{2}+d_{3} W^{3}}
$$

at the time $P>0.5$, parameters $W=\sqrt{-2 \ln (1-P)}$,

$$
S P E I=W-\frac{c_{0}+c_{1} W+c_{2} W^{2}}{1+d_{1} W+d_{2} W^{2}+d_{3} W^{3}}-W
$$

among them $c_{0}=2.515517, c_{1}=0.802853, c_{2}=0.010328, d_{1}=1.432788$, $d_{2}=0.189269, d_{3}=0.001308$.

\subsection{Regional Climate Model Scenario Data Revision}

Due to the limited data simulation ability of the current climate model, there is a certain error between the simulated factor value and the actual observation value, which brings certain uncertainty to the estimation in the future scenario. Therefore, when applying the mode data, it is very necessary to perform data matching. The revised method adopted in this paper refers to Song Yanling's (2012) revised method. 
The revised method for monthly mean temperature is:

$$
\text { Correction }(c f)_{\text {month }}=M_{\text {month }}^{G C M \text { scenario }}+\left(\overline{M_{\text {month }}^{\text {obs }}}-\overline{M_{\text {month }}^{G C M b a s e l i n e}}\right)
$$

The monthly average precipitation correction method is:

$$
\text { Correction }(c f)_{\text {month }}=M_{\text {month }}^{\text {GCMscenario }}+\left(\overline{M_{\text {month }}^{\text {obs }}}-\overline{M_{\text {month }}^{\text {GCMaseline }}}\right)
$$

where, Correction $(c f)_{\text {month }}$ is the result of the revised month of the future climate scenario simulated by the climate model, the month value is January and February... December, $M_{\text {month }}^{\text {GCMscenario }}$ is the monthly data of future climate scenarios simulated by the climate model, $\overline{M^{o b s}}$ is the average value of historical observations, and $\overline{M^{o b s}}$ is the average value of the benchmark month of climate model simulation.

In addition, we defined the change rate of corn yield per unit area $Y_{p}$ as the percentage of corn yield per unit area in that year $Y_{i}$ minus the average yield per unit area in the previous three years after the average yield per unit area in the previous three years, namely:

$$
Y_{p}=\left(Y_{i}-\frac{1}{3} \sum_{n=i-3}^{i-1} Y_{n}\right) / \frac{1}{3} \sum_{n=i-3}^{i-1} Y_{n}
$$

In addition, the cumulative sum of the negative SPEI index for the maize growing season (May-September) was defined as the cumulative SPEI index to explore the link between the cumulative SPEI index and the rate of change in maize yield.

\section{CMIP5 Mode Evaluation}

First, the model data is interpolated daily to 114 stations, and the annual precipitation and annual average temperature of 114 stations in the northeast region are calculated. The annual precipitation and annual average temperature of nine CMIP5 models from 1961 to 2000. From the model simulation of annual precipitation and annual average temperature, the model data generally simulates the annual precipitation in the northeast region, while the annual average temperature simulation is generally low. This is consistent with the previous research conclusions (Xu \& Xu, 2012; Chen et al., 2014). This error in modelling is also present in previous global models and may be related to the limited response of global models to complex terrain (Wu et al., 2015). In order to further determine the model's simulation of annual precipitation and temperature in Northeast China, Table 2 gives the correlation coefficient, variance and root mean square error of the nine model data and observation data. From the correlation coefficient of annual precipitation, the GFDL-ESM2G model has the highest correlation with the observed data, and the correlation coefficient reaches 0.498 . The significance test of 0.01 is passed, indicating that the GFDL-ESM2G model is the closest to the precipitation simulation trend and the observed data. From the perspective of variance and root mean square error, the GFDL-ESM2G model is ranked at a medium level in all nine modes. It can be seen that the 
Table 2. Comparative analysis of annual precipitation, temperature and observation data in northeastern China simulated by CMIP5 model.

\begin{tabular}{ccccccc}
\hline & \multicolumn{3}{c}{ rainfall } & \multicolumn{3}{c}{ air temperature } \\
\cline { 2 - 7 } mode & $\begin{array}{c}\text { Correlation } \\
\text { coefficient }\end{array}$ & variance & $\begin{array}{c}\text { Root mean } \\
\text { square error }\end{array}$ & $\begin{array}{c}\text { Correlation } \\
\text { coefficient }\end{array}$ & variance & $\begin{array}{c}\text { Correlation } \\
\text { coefficient }\end{array}$ \\
\hline ACCESS1 & -0.175 & 82.37 & 121.41 & 0.277 & 0.78 & 1.10 \\
BCC-CSM1-1 & -0.036 & 69.97 & 126.11 & 0.319 & 0.69 & 2.27 \\
CCSM4 & -0.256 & 89.47 & 247.22 & 0.212 & 0.82 & 1.16 \\
CSIRO-Mk3-6-0 & -0.063 & 82.49 & 195.25 & 0.308 & 0.61 & 1.88 \\
GFDL-ESM2G & 0.498 & 77.99 & 158.54 & 0.206 & 0.78 & 1.19 \\
IPSL-CM5A-MR & -0.184 & 74.98 & 302.17 & 0.443 & 0.57 & 1.95 \\
MPI-ESM-LR & 0.231 & 81.91 & 255.89 & 0.085 & 0.55 & 1.01 \\
MRI-CGCM3 & 0.113 & 78.64 & 104.55 & 0.306 & 0.61 & 2.21 \\
NorESM1-M & 0.153 & 77.57 & 202.23 & 0.449 & 0.76 & 2.44 \\
\hline
\end{tabular}

GFDL-ESM2G model has a better simulation effect on precipitation in the Northeast. From the simulation effect of temperature, the model simulates the temperature better than precipitation. From the simulation trend, the trend of NorESM1-M mode and IPSL-CM5A-MR mode and observation data is the best, and the correlation coefficients between the two are 0.449 and 0.443 , respectively, both exceeding the significance level of 0.01 . The GFDL-ESM2G model has a correlation coefficient of 0.206 for temperature prediction and observation data in Northeast China, and the correlation trend is good, and its root mean square error is better than NorESM1-M mode and IPSL-CM5A-MR mode, indicating that GFDL-ESM2G mode is northeast. The regional temperature deviation is better simulated. In summary, based on the better correlation between GFDL-ESM2G model precipitation data and observation data, and precipitation is an important factor affecting regional drought, this paper selects GFDL-ESM2G model data to estimate the drought in Northeast China.

\section{Drought and Corn Yield Change Rate in Northeast China}

\subsection{Drought Trend in Northeast China}

The calculation of SPEI is based on the assumption that the probability distribution of the cumulative water deficit sequence at a certain time scale obeys the log-logistic probability distribution. Therefore, when the empirical probability distribution of the cumulative water deficit sequence at a certain time scale is approximately consistent with the log-logistic probability distribution, it is considered that the SPEI analysis of the scale is applicable to the sequence in winter, when the time scale is less than 3 months, southern Xinjiang The SPEI values calculated in the northwestern part of Tibet and the north China to Hetao area are not reliable because the sample does not obey the assumed log-logistic distribution, and the calculated SPEI value is reliable when the time scale is greater 
than 3 months; Regardless of any time scale, the Chinese-wide sample basically conforms to the assumed log-logistic distribution, and the calculated SPEI index is reliable (Zhuang, et al. 2013; Wang \& Chen, 2014). Therefore, the SPEI sequence time scale calculated in this paper is 3 months.

Figure 2 shows the average distribution of the intergenerational cumulative SPEI index for the corn growing season in Northeast China from 1961 to 2010. It can be seen that in the 1960s and 1970s (Figure 2(a), Figure 2(b)), the drought situation in the northeast region was weak; in the 1980s (Figure 2(c)), the drought mainly occurred in the southeastern part of Inner Mongolia; (Figure 2(d)), the drought in southeastern Inner Mongolia was alleviated, while the drought in northern Inner Mongolia developed, and the drought in Liaoning and Jilin increased. In the $21^{\text {st }}$ century (Figure $2(\mathrm{e})$ ), the drought in the northeast region increased significantly, especially in eastern and northern Inner Mongolia. District, the drought situation is grim. From 1961 to 2010, the drought in Northeast China showed an aggravating trend, especially in the northern part of the Northeast and eastern Inner Mongolia. This is consistent with the results of previous studies (Zou \& Zhang, 2008; Yang et al., 2015).
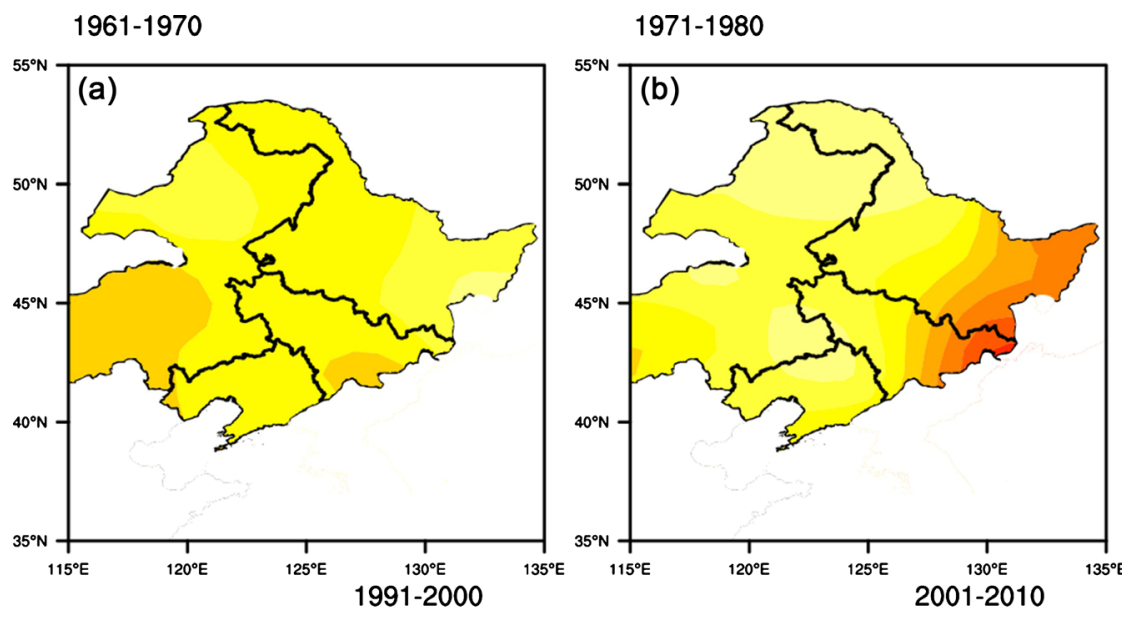

$1981-1990$

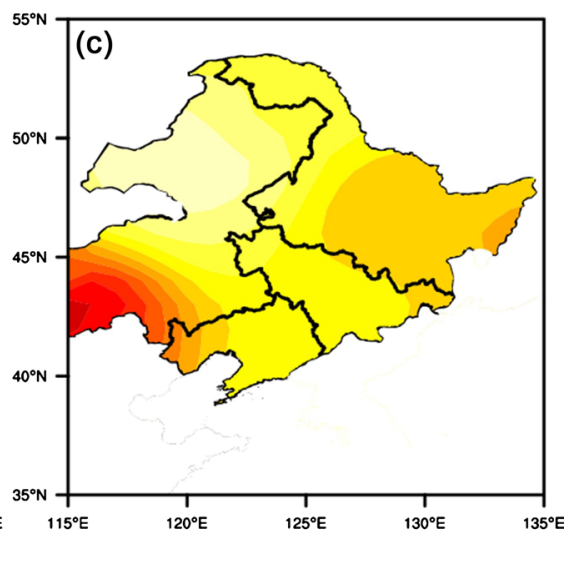

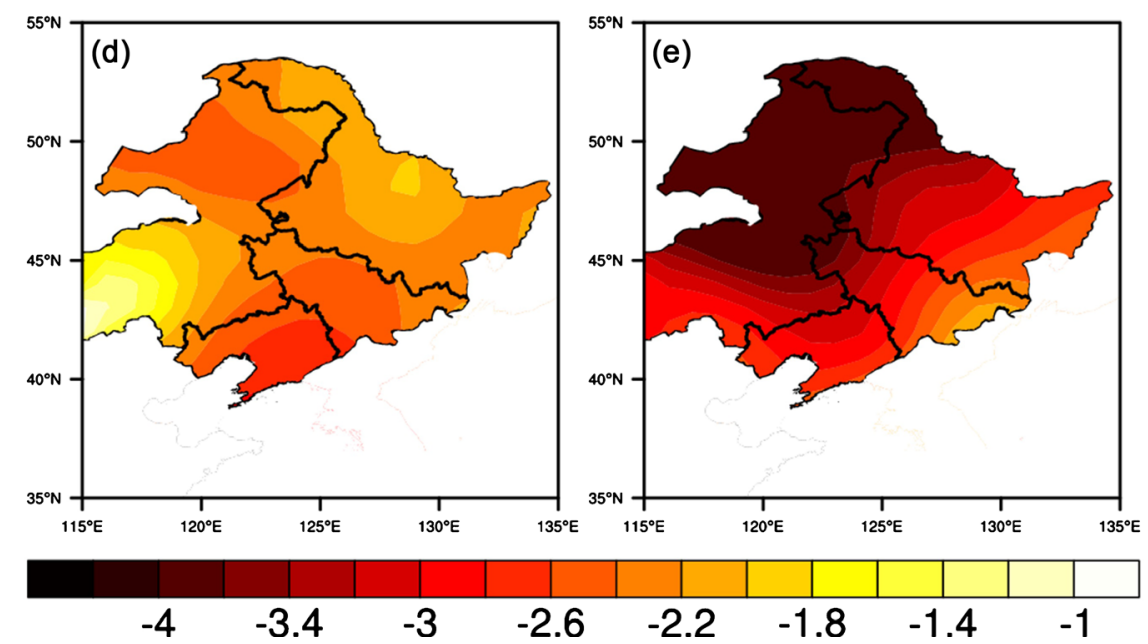

Figure 2. Drought change in Northeast China using SPEI calculated from 1961 to 2010 ((a) 1961-1970, (b) 1971-1980, (c) 1981-1990, (d) 1991-2000, (e) 2001-2010)). 


\subsection{Drought and Corn Yield}

The above analysis shows that the drought in Northeast China has a clear trend, and the drought in Northeast China has a significant impact on the corn yield of the main crops. Figure 3 shows the correlation between the rate of change of maize yield and the cumulative SPEI index in Northeast China. It can be seen from Figure 3(a) that the rate of change in maize yield in Northeast China is significantly positively correlated with the cumulative SPEI index, with a correlation coefficient of 0.378 , exceeding The significance level of 0.01 ( $\mathrm{n}=45, \alpha_{0.01}=$ 0.372 ), that is, when the negative value of the cumulative SPEI index is larger, the yield reduction of maize yield in Northeast China is higher. It is worth
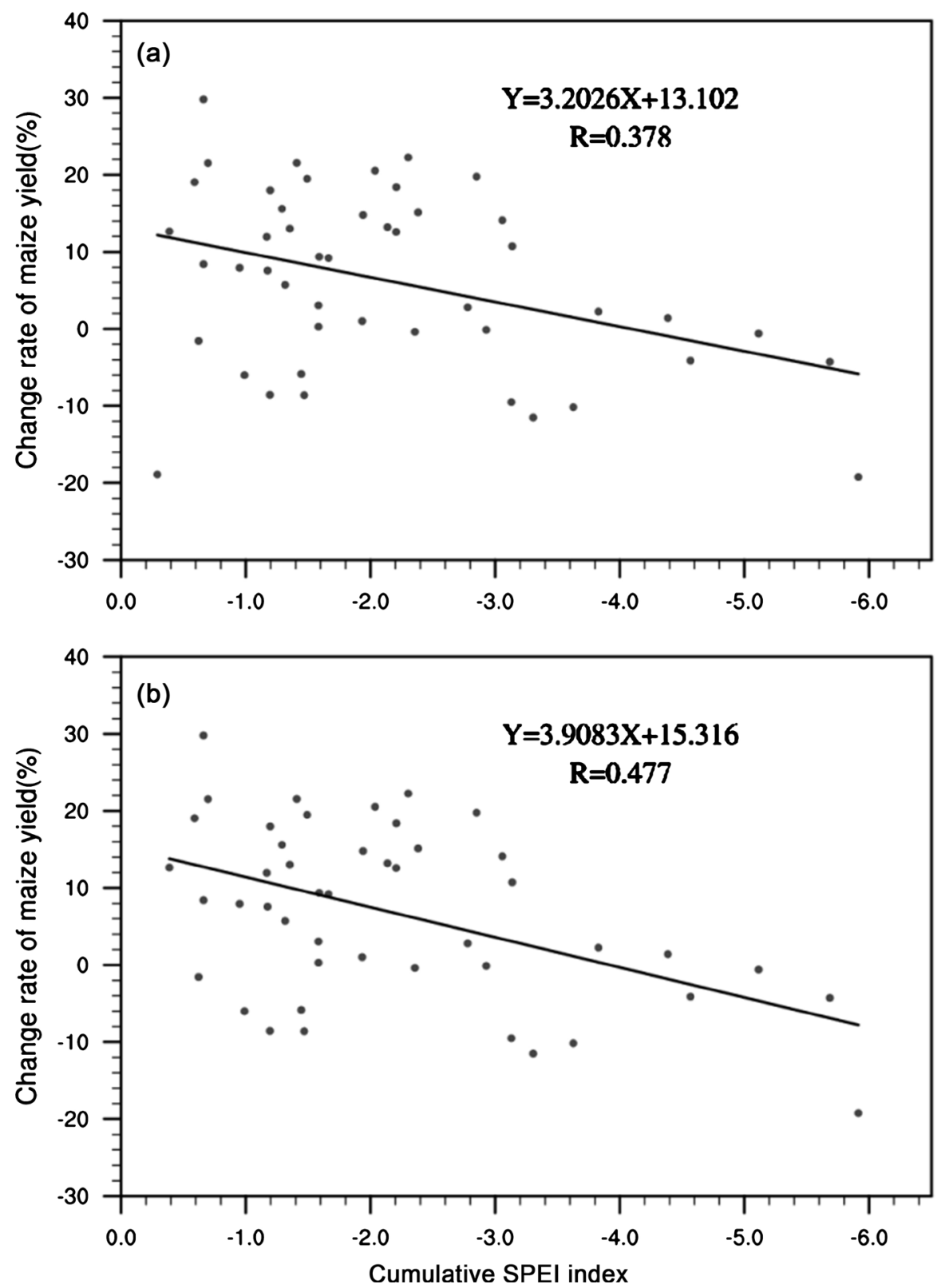

Figure 3. Relationship between corn yield change rate and cumulative SPEI index in Northeast China, (a) 1961-2010, (b) Excluding 1969 data. 
noting that in some abnormal years, the yield per unit of corn yield is large, but the cumulative SPEI index is not high. As shown in 1969, the cumulative SPEI index for May-September is only -0.29 , but the maize in Northeast China. The yield per unit was reduced by $18 \%$. The precipitation and temperature of the 1969 corn growth period were calculated. The precipitation from May to September in this year was $478.7 \mathrm{~mm}$ (average climatic state was $432.1 \mathrm{~mm}$ ), and the average temperature was $16.8^{\circ} \mathrm{C}$ (average climatic state was $18.0^{\circ} \mathrm{C}$ ). In this year, the corn has a lot of precipitation during the growth period and the temperature is low. It is indicated that in some abnormal years, in addition to drought factors, the northeast corn production is reduced, and other factors affecting corn yield such as flood, low temperature and hail are also present (Ma, Xu, \& Pan, 2012). If this abnormal year is excluded, the correlation coefficient between corn change rate in Northeast China and cumulative SPEI index from May to September is 0.477 , and the correlation coefficient is greatly improved, indicating that there are many factors affecting maize yield in Northeast China, but drought is affecting corn yield in Northeast China. Important factors have a significant impact on the increase and decrease of corn yield in Northeast China.

\section{Drought Trend in Northeast China in the Next 30 Years}

In order to further study the future drought trend in Northeast China, this paper uses the GFDL-ESM2G model to estimate the drought trend of the Northeast region in the next 30 years (2020-2050).

\subsection{Precipitation and Temperature in Northeast China in the Next 30 Years}

In this paper, based on the regional climate model scenario data correction method, based on the 1971-2000 observation data and GFDL-ESM2G model data, the correction coefficient of precipitation and temperature in stations in Northeast China is obtained. Figure 4 is a comparison of pre- and post-correction of precipitation and temperature in stations in Northeast China. For precipitation (Figure $4(\mathrm{a})$ ), the model overestimates the precipitation in winter and spring in Northeast China, and seriously underestimates summer precipitation, especially 7 Precipitation in the month and August. The revised precipitation (Figure 4(c)) shows that the high precipitation in spring and winter is eliminated, and the summer precipitation is also close to the observed value. For the temperature (Figure 4(b), Figure 4(d)), the pre-corrected mode temperature is low in winter, and the other months are similar to the overall temperature distribution pattern and observation. The corrected model temperature is basically consistent with the observed data. Finally, the paper uses the station correction coefficient to correct the temperature and precipitation in the next three scenarios of GFDL-ESM2G mode.

Figure 5 shows the sequence of annual precipitation and average temperature 

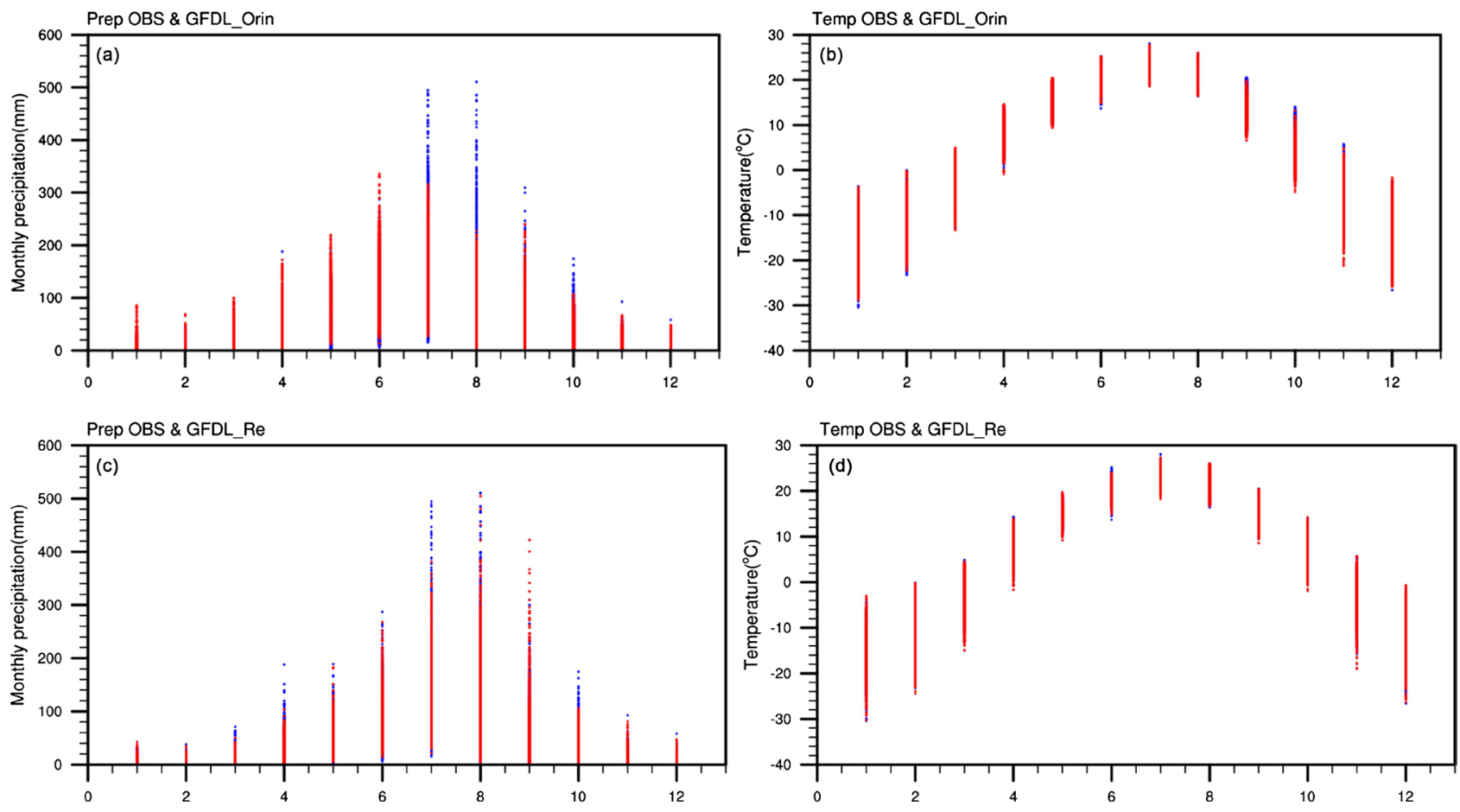

Notes: X-axis, 1, 2, ..., 12 denote the month of Jan, Feb, ..., Dec in a year.

Figure 4.Comparison of ((a), (c)) monthly precipitation, ((b), (d)) monthly mean temperature observation (blue) from 1971-2000 in Northeast China, and GFDL-ESM2G simulated value (red) before and after correction.

change in Northeast China from 2020 to 2050. The following three scenarios of GFDL-ESM2G model show that the annual precipitation in Northeast China in the future (2020-2050) under RCP2.6 and RCP4.5 scenarios The increase trend, especially in the RCP4.5 scenario, the annual precipitation increased significantly, reaching $3.2 \mathrm{~mm} / \mathrm{a}$. Under the RCP2.6 scenario, the annual precipitation increased by $0.5 \mathrm{~mm} / \mathrm{a}$; in the RCP8.5 scenario, the future. The annual precipitation in the northeastern region shows a weakening trend with a decreasing range of $-1.4 \mathrm{~mm} / \mathrm{a}$. The GFDL-ESM2G model predicts the future temperature in the northeast region. Under the three scenarios of RCP, the annual average temperature in the northeast region shows a warming trend. Among them, the RCP8.5 scenario has the fastest temperature increase, the temperature increase rate reaches $0.5^{\circ} \mathrm{C} / 10 \mathrm{a}$, and the $\mathrm{RCP} 4.5$ scenario temperature increase rate is second, $0.18^{\circ} \mathrm{C} / 10 \mathrm{a}$, while in the RCP2.6 scenario, the temperature increase rate is the slowest., $0.02^{\circ} \mathrm{C} / 10 \mathrm{a}$. In the three scenarios of $\mathrm{RCP}$, the temperature increase rate in Northeast China is lower than that in China in 2011-2100. The RCP2.6 scenario is $0.06^{\circ} \mathrm{C} / 10 \mathrm{a}$, the $\mathrm{RCP} 4.5$ scenario is $0.24^{\circ} \mathrm{C} / 10 \mathrm{a}$, and the RCP8.5 scenario is $0.63^{\circ} \mathrm{C} / 10 \mathrm{a}$. ( $\mathrm{Xu} \& \mathrm{Xu}, 2012$ ), it can be seen that the trend of warming in Northeast China is consistent with the three scenarios of RCP, but the rate of warming is lower than the national average.

\subsection{Future Drought Trends in Northeast China}

According to the monthly precipitation and temperature, the SPEI index of 

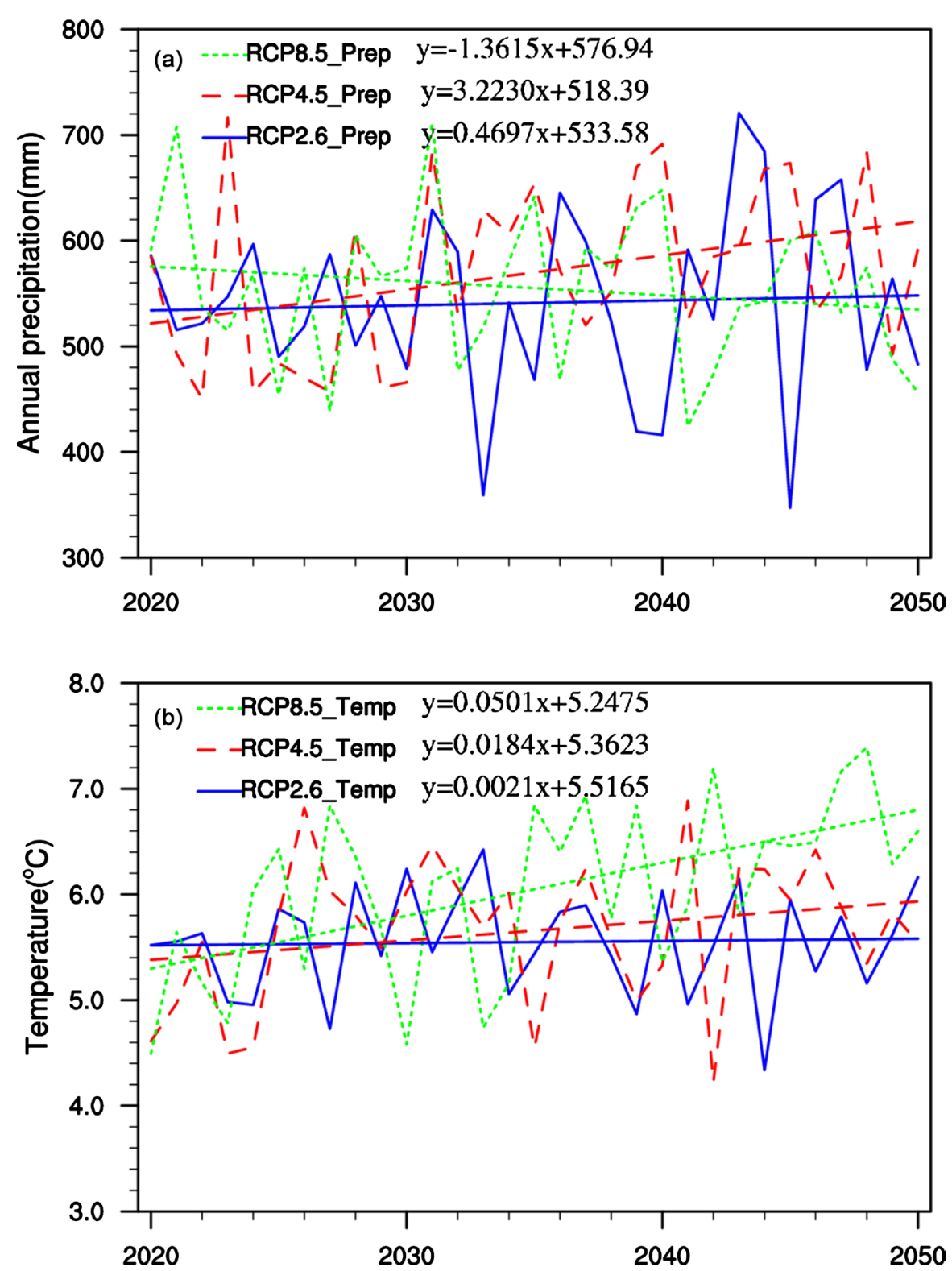

Figure 5. Annual precipitation (a) and average temperature (b) changes in Northeast China from 2020 to 2050.

Northeast China is calculated from 2020 to 2050, and the northeast drought trend during the growth of maize in Northeast China is studied. Figure 6(a) shows the annual variation of the cumulative SPEI index from May to September in Northeast China from 2020 to 2050, indicating that the drought in the northeast region will be aggravated in the RCP2.6 and RCP8.5 scenarios under the three scenarios of RCP, especially RCP8.5. Under the scenario, the drought trend is obvious. In the RCP4.5 scenario, drought has shown signs of slowing down, most likely due to increased precipitation in the RCP4.5 scenario. According to the correlation between the change rate of corn yield and the cumulative SPEI index from May to September, the change trend of corn yield per unit rate in the next three scenarios in Northeast China was calculated (Figure 6(b)). The results 

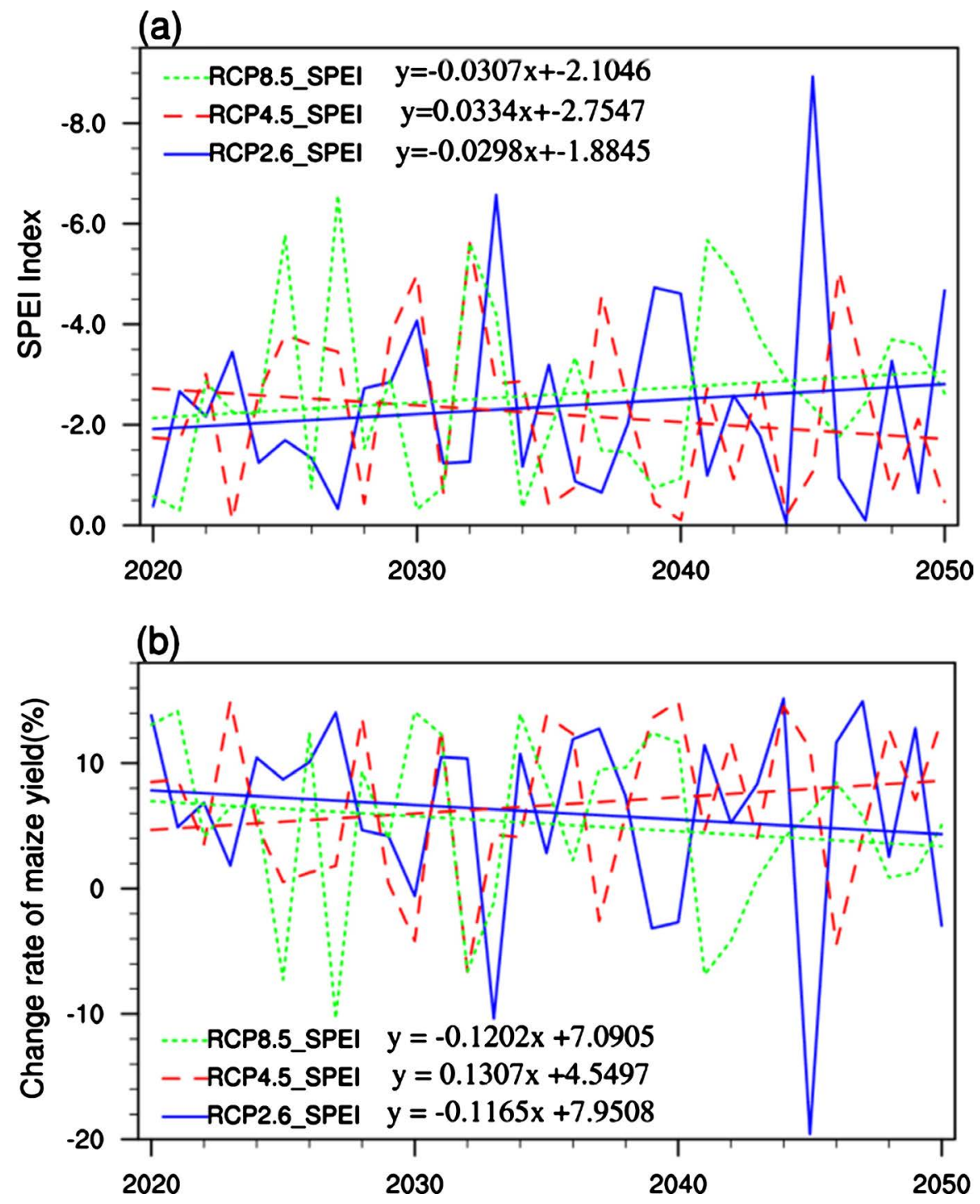

Figure 6. Trends of cumulative SPEI index from May to September in Northeast China during 2020-2050 RCP (a) and corn yield change rate (b).

showed that under the RCP2.6 and RCP8.5 scenarios, the yield change rate of maize in Northeast China showed a downward trend, indicating that climate warming caused the drought in Northeast China to increase, which had a negative impact on corn yield increase. In severe drought years, drought may cause Northeast China. Maize severely reduced production. However, under the RCP4.5 scenario, drought has little effect on corn yield.

This paper further analyzes the distribution of drought trends in Northeast China from 2020 to 2050. Under the RCP2.6 and RCP8.5 scenarios, almost all droughts in Northeast China are increasing. Under the RCP2.6 scenario, the drought situation in eastern Inner Mongolia will be in the future. It is even more severe. In the RCP8.5 scenario, it appears as the southern part of the eastern region, especially in Liaoning Province. The drought in the northeast region is slowing down in the RCP4.5 scenario. From the perspective of the interdecadal 
development of the northeastern region, compared with the first decade of the 21 st century, the drought in the northeast region showed a decreasing trend under the RCP2.6 and RCP4.5 scenarios. Under the RCP8.5 scenario, the northeast region was 2020-2040. The drought has also eased, and in the 1940s, the drought in the northeast was severe. In the RCP2.6 scenario, in 2020-2030, the drought was mainly distributed in the northern part of the northeastern region, and in 2031-2040, the arid regions were mainly located in the southwestern part of the northeastern region, and the northeastern region was drought-ridden from 204 to 1050; RCP4.5. In the scenario, from 2020 to 2030, the northeastern region was in a drought, and in 2031-2040, the drought mainly occurred in the northeastern part of the Northeast, and most of Jilin Province and Liaoning Province were in a drought. By 2041-5050, the drought in Northeast China continued to weaken. Under the RCP8.5 scenario, the drought in the northeastern region was biased from 2020 to 2030. By 2031 to 1240, the drought in the northeast region was weakened. The drought was mainly located in Jilin Province. During the period of 2041-2050, the drought in the northeast region was severe than other periods.

\section{Conclusion}

This paper firstly compares the data of 9 CMIP5 models with the observation data of Northeast China. Based on the SPEI index, this paper studies the drought trend in Northeast China and the change rate of corn yield, and estimates the drought and corn yield in Northeast China. The conclusions are as follows:

The comparison of the nine model data and observation data of CMIP5 shows that the model data are generally more than the precipitation simulation in Northeast China, but the temperature simulation is low. The GFDL-ESM2G model has the best simulation effect on annual precipitation in Northeast China, and its correlation coefficient with observation data is 0.498 , and the correlation coefficient with annual average temperature in Northeast China is 0.206 . Because drought is highly dependent on precipitation, this paper selects GFDL-ESM2G model data to estimate drought and maize yield in Northeast China.

Based on the cumulative SPEI drought index analysis, the northeastern region showed a significant drying trend from 1961 to 2010. The drying center was primarily located in the northeastern part of the northeast and the eastern part of Inner Mongolia. Correlation analysis between cumulative SPEI index and Corn yield change rate in Northeast China showed that there was a significant positive correlation between cumulative SPEI index and corn yield change rate in Northeast China, that is, the more drought in the Northeast China (the greater negative SPEI index), the more the reduction in corn yield.

The Northeast is China's main commodity grain production base. The drought problem in the Northeast is very complicated. In addition to the impact of precipitation, the drought is also affected by factors such as temperature. This paper selects the GFDL-ESM2G model data to estimate the future drought trend and corn yield change in Northeast China. Although the study shows that the 
GFDL-ESM2G model simulates the precipitation in Northeast China better than other models, the GFDL-ESM2G model simulates the future of Northeast China. The climate scenario still has a lot of uncertainty.

\section{Acknowledgements}

This paper was supported by National Key R\&D Program of China (2018YFC1505605) and China Special Fund for Meteorological Research in the Public Interest (GYHY201506019).

\section{Conflicts of Interest}

The authors declare no conflicts of interest regarding the publication of this paper.

\section{References}

Chen, X. C., Xu, Y., Xu, C. H. et al. (2014). CMIP5 Global Model for Assessment of Precipitation Simulation Capacity in China. Advances in Climate Change Research, 10, 217-225.

Cheng, Y. Q., \& Zhang, P. Y. (2005). Regional Pattern Change of China's Grain Production and Response of Commodity Grain Bases in Northeast China. Geography Science, $25,513-520$

Hu, S., Mo, X. G., \& Lin, Z. H. (2015). Temporal and Spatial Variation Trends of Drought in Northern China under Future Climate Scenarios. Arid Land Geography, 38, 239-248.

IPCC (2013). Climate Change 2013: The Physical Science Basis, Contribution of Working Group I to the Fifth Assessment Report of the Intergovernmental Panel on Climate Change. Cambridge, United Kingdom and New York, NY, USA: Cambridge University Press.

Liu, K., \& Jiang, D. B. (2015). Analysis of Dryness/Wetness over China Using Standardized Precipitation Evapotranspiration Index Based on Two Evapotranspiration Algorithms. Chinese Journal of Atmospheric Sciences (in Chinese), 39, 23-36.

Ma, J. Y., Xu, W. L., \& Pan, W. (2012). The Change of Agro-Meteorological Disasters in Northeast China and Its Impact on Grain Yield. Chinese Journal of Agricultural Meteorology, 33, 283-288.

Song, Y. L. (2012). Impact of Climate Change on China's Agriculture (pp. 69-81). Beijing: Meteorological Press.

Sun, B. F., Zhao, H., \& Wang, X. K. (2015). Spatial and Temporal Characteristics of Drought in Northeast China Based on Standard Precipitation Evaporation Index (SPEI). Chinese Journal of Ecology, 24, 22-28.

Thornthwaite, C. W. (1948). An Approach toward a Rational Classification of Climate. Geographical Reviews, 38, 55-94.

Vicente Serrano, S. M., Beguería, S., \& López-Moreno, J. I. (2010). A Multiscalar Drought Index Sensitive to Global Warming: The Standardized Precipitation Evapotranspiration Index-SPEI. Journal of Climate, 23, 1696-1718.

https://doi.org/10.1175/2009JCLI2909.1

Wang, L., \& Chen, W. (2014). Applicability Analysis of Standardized Precipitation Evapotranspiration Index in Drought Monitoring in China. Plateau Meteorology, 33, 
423-431

Wu, J., Zhou, B., \& Xu, Y. (2015). Response of China's Average Precipitation and Extreme Precipitation to Climate Warming: Simulation Evaluation and Estimation of CMIP5 Model. Chinese Journal of Geophysics, 58, 3048-2060.

Xu, C. H., \& Xu, Y. (2012). The Projection of Temperature and Precipitation over China under RCP Scenarios Using a CMIP5 Multi-Model Ensemble. Atmospheric and Oceanic Science Letters, 5, 527-533. https://doi.org/10.1080/16742834.2012.11447042

$\mathrm{Xu}, \mathrm{Y} ., \quad \& \mathrm{Xu}, \mathrm{C} . \mathrm{H}$. (2012). Preliminary Assessment of Simulations of Climate Changes over China by CMIP5 Multi-Models. Atmospheric and Oceanic Science Letters, 5, 489-494. https://doi.org/10.1080/16742834.2012.11447041

Yang, X., Ming, B., Tao, H. et al. (2015). Drought Time and Space Distribution Characteristics of Spring Maize Area in Northeast China and Its Impact on Yield. Chinese Journal of Eco-Agriculture, 23, 758-767.

Yang, Y., Zheng, Q., Luo, J. et al. (2015). Practical Agricultural Meteorological Indicators (pp. 11-15). Beijing: Meteorological Press.

Yu, H., Zhao, J., \& Yu, H. (2017). Analysis of Impacts of Climate Change on Chilling Damage of Interdecadal Northeast China. Chinese Journal of Agricultural Resources and Regional Planning, 38, 113-122.

Yu, M. X., Li, Q. F., Hayes, M., Svoboda, M., \& Heim, R. (2014). Are Droughts Becoming More Frequent or Severe in China Based on the Standardized Precipitation Evapotranspiration Index: 1951-2010? International Journal of Climatology, 34, 545-558. https://doi.org/10.1002/joc.3701

Zhang, M., Liu, Z., Yang, X. et al. (2016). Temporal and Spatial Distribution Characteristics of Agricultural Meteorological Disasters of Major Crops in China under Climate Change: Delayed Cold Damage of Spring Maize in Northeast China. Chinese Journal of Agrometeorology, 37, 599-610.

Zhuang, S., Zuo, H., Ren, P. et al. (2013). Application of Standardized Precipitation Evaporation Index in China. Climate and Environmental Research, 18, 617-625.

Zou, X., \& Zhang, Q. (2008). Preliminary Study on Drought Change in China in the Last Half Century. Journal of Applied Meteorology, 19, 679-687. 